\title{
Expression of inflammation-mediated cluster of genes as a new marker of canine mammary malignancy
}

\author{
K. M. Pawłowski • A. Homa • M. Bulkowska • \\ K. Majchrzak • T. Motyl • M. Król \\ Accepted: 13 February 2013 / Published online: 24 February 2013 \\ (C) The Author(s) 2013. This article is published with open access at Springerlink.com
}

\begin{abstract}
Because canine mammary tumours constitute a serious clinical problem and there are no good prognostic markers (only histopathological variables are used), the aim of the presented study was to find new malignancy markers as well as to identify intracellular pathways and biological processes characteristic for canine mammary malignancy. We compared gene expression of the most malignant mammary tumours (poorly differentiated cancers of the 3rd grade of malignancy) with less malignant tumours (well differentiated cancers of the 1 st grade of malignancy). The results of our study indicated that in dogs the number of tumour-infiltrating myeloid cells or expression of myeloid-specific antigens by cancer cells is related to the cancer progression and may constitute a new marker of malignancy, however further studies in this field are required.
\end{abstract}

Keywords Canine mammary cancer · Malignancy markers · Microarrays $\cdot$ Real-time qPCR $\cdot$ Myeloid cells infiltration

K. M. Pawłowski • A. Homa • M. Bulkowska • T. Motyl •

M. Król $(\bowtie)$

Department of Physiological Sciences,

Faculty of Veterinary Medicine, Warsaw University

of Life Sciences-WULS, Nowoursynowska 159,

02-776 Warsaw, Poland

e-mail: magdalena_krol@sggw.pl

K. M. Pawłowski

Department of Large Animal Diseases with Clinic, Faculty of Veterinary Medicine, Warsaw University of Life Sciences - WULS, Nowoursynowska 100, 02-797 Warsaw, Poland

\section{K. Majchrzak}

Department of Animal Environment Biology, Faculty of Animal Sciences, Warsaw University of Life Sciences-WULS, Ciszewskiego 8, 02-786 Warsaw, Poland

\section{Introduction}

Spontaneous mammary tumours are the most prevalent type of malignant neoplasm in the bitch and woman with the three times over incidence in dog (MacEwen 1990). About $50 \%$ of all the mammary tumours are malignant (Misdorp 2002). The aetiology of mammary cancer is very complex and not clearly understood. The known mediators of tumourigenesis in both species are: genetic, hormonal, dietary, environmental and carcinogenic factors (Russo and Russo 1998). Moreover, both species live in the same conditions, thus the dog is a good model for breast cancer studies.

The role of oestrogens, progestins and growth hormone in canine mammary cancer development has been documented (Pawłowski et al. 2012). That is why mainly affected are not spayed female dogs in the middle age. The early ovariectomy reduces risk of mammary cancer development (Misdorp 1991). However, the high morbidity and mortality rate, which is caused by poor diagnostics and ineffective treatment strategies makes this problem still actual in both humans and dogs. The conventional approach to cancer therapy provide treatment according to the organ in which the cancer originates. However, different intracellular signalling pathways are perturbed in the various cancers even if they represent the same type. Thus, the patients with the same type of cancer often have dissimilar genetic defects in their tumours and respond in a heterogeneous manner to anticancer agents (Veer van't and Bernards 2008). Moreover, the diagnostic methodologies available in veterinary oncology may still be considered to be in progress. So far, only histopathological variables (tumour size, lymph node status, vascular invasion and tumour grade of differentiation) are used as prognostic parameters (Manuali et al. 2012).

Thus, the aim of the presented study was to find intracellular pathways and biological processes characteristic for canine mammary malignancy. We compared gene expression of the most malignant mammary tumours (poorly differentiated 
Table 1 Primers sequences used in this study and their annealing optimal temperature and time. The mRNA sequences of key genes were obtained from NCBI database. Primers were designed using PRIMER3 software (free on-line access) and checked using Oligo
Calculator (free on-line access) and Primer-Blast (NCBI database). Rps19 gene was used as a non-regulated reference gene for normalization of target gene expression (Brinkhof et al. 2006; Etschmann et al. 2006)

\begin{tabular}{lllcc}
\hline Gene symbol & Forward primer & Reverse primer & $\begin{array}{l}\text { Optimum annealing } \\
\text { temp. }\left({ }^{\circ} \mathrm{C}\right)\end{array}$ & $\begin{array}{l}\text { Optimum } \\
\text { annealing time }(\mathrm{sec})\end{array}$ \\
\hline il15 & CAGACTCACCGAAGAGGAAA & CTGCTGTGAAGTCTGGGAGT & 60 & 6 \\
ergic2 & TGCCATCGTCTGCTACATTA & CAGTCGCCTCTCACTCTCAT & 61 & 9 \\
elspb1 & CTTTCACATCACTGCACTCG & GTGTGTTGGGAGGTGAGTTC & 60 & 6 \\
extl3 & AGCTTGCTGGTGAAAAGGAC & TTATAGTCAAGGGCATATCC & 60 & 6 \\
$r p s 19$ & CCTTCCTCAAAAAGTCTGGG & GTTCTCATCGTAGGGAGCAAG & 61 & 10 \\
\hline
\end{tabular}

cancers of the 3rd grade of malignancy) with less malignant tumours (well differentiated cancers of the 1st grade of malignancy) in order to find new diagnostic and prognostic markers.

\section{Materials and methods}

Tissue samples

Tumour samples of canine mammary cancers were obtained from patients subjected to surgery. The tumours then, were divided into two equal halves, one of them was fixed in $10 \%$ neutral buffered formalin and routinely embedded in paraffin to perform histological assay. The other was snap frozen in liquid nitrogen and stored in $-80{ }^{\circ} \mathrm{C}$. Four $\mu \mathrm{m}$ samples from paraffin blocks were fixed on glass slides, stained with haematoxylin - eosin (HE) and examined by certified pathologists (prof. Dr. hab. Elżbieta Malicka and Dr. Izabella Dolka, both from the Warsaw University of Life Sciences, Poland). The immunohistochemical examination of cytokeratin, vimentin, smooth muscle actin, s100 protein and p63
Fig. 1 Gene Spring (Agilent, USA) diagrams of: a. boxplots showing median relative signal measured for each microarray; b. quality control gene expression in both microarray experiments (in dye-swaps) shows highly repeatable results; c. all genes expression in both microarray experiments (in dye-swaps), genes that differed significantly at $p$ value $<0.01$ with fold cut-off $=1.5$ (unpaired t-test and Benjamin-Hochberg $\mathrm{FDR}<5 \%$ correction) are showed as blue points (they were taken to the further analyses)

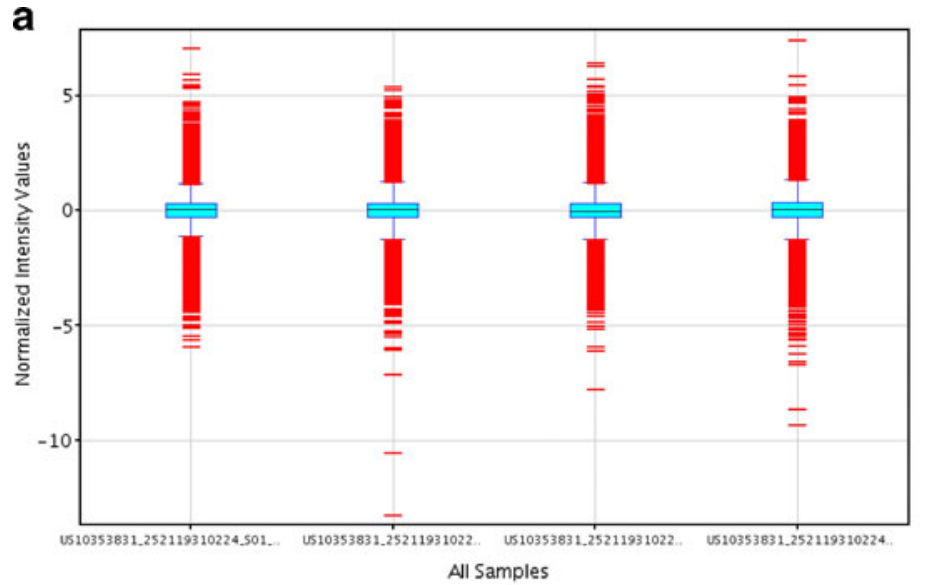

b

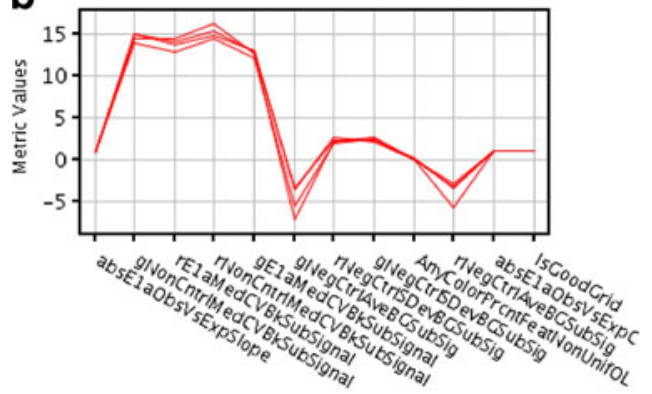

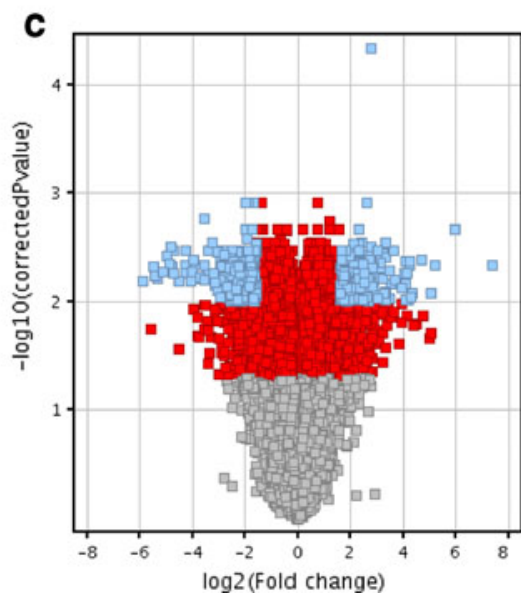


Table 2 The list of up-regulated genes $(\uparrow)$ in canine mammary cancers of the 3rd grade of malignancy compared with the canine mammary cancers of the 1 st grade of malignancy. Data was analyzed using Gene Spring software (Agilent, USA), $p<0.005$, Fold change $>3$

\begin{tabular}{|c|c|c|c|}
\hline & Fold Change & Gene symbol & Description \\
\hline 1 & $\uparrow 5.0125217$ & IL8 & Canis lupus familiaris interleukin 8 (IL8), mRNA [NM_001003200] \\
\hline 2 & $\uparrow 4.714284$ & FABP1 & $\begin{array}{l}\text { Fatty acid binding protein Fragment [Source:UniProtKB/TrEMBL;Acc:Q95KW5] } \\
\text { [ENSCAFT00000011880] }\end{array}$ \\
\hline 3 & $\uparrow 4.2913084$ & MMP1 & Matrix metalloproteinase 1 \\
\hline 4 & $\uparrow 4.2044907$ & EXTL3 & Exostosin-like 3;EXTL3; ortholog \\
\hline 5 & $\uparrow 3.957821$ & CNGA1 & $\begin{array}{l}\text { Canis lupus familiaris cyclic nucleotide gated channel alpha } 1 \text { (CNGA1), mRNA } \\
\text { [NM_001003222] }\end{array}$ \\
\hline 6 & $\uparrow 3.925793$ & NELL2 & $\begin{array}{l}\text { PREDICTED: Canis familiaris similar to Protein kinase C-binding protein NELL2 } \\
\text { precursor (NEL-like protein 2) (Nel-related protein 2), transcript variant } 2 \text { (LOC477636), } \\
\text { mRNA [XM_846523] }\end{array}$ \\
\hline 7 & $\uparrow 3.9208682$ & CNGA1 & $\begin{array}{l}\text { Canis lupus familiaris cyclic nucleotide gated channel alpha } 1 \text { (CNGA1), mRNA } \\
\text { [NM_001003222] }\end{array}$ \\
\hline 8 & $\uparrow 3.416843$ & MMP3 & $\begin{array}{l}\text { Canis lupus familiaris matrix metallopeptidase } 3 \text { (stromelysin 1, progelatinase) } \\
\text { (MMP3), mRNA [NM_001002967] }\end{array}$ \\
\hline 9 & $\uparrow 3.2882302$ & NELL2 & NEL-like 2 (chicken) [Source:HGNC Symbol;Acc:7751] [ENSCAFT00000015264] \\
\hline 10 & $\uparrow 3.0424755$ & MTMR10 & $\begin{array}{l}\text { PREDICTED: Canis familiaris similar to phosphatidylinositol-3-phosphatase associated } \\
\text { protein, transcript variant } 4 \text { (LOC479016), mRNA [XM_851476] }\end{array}$ \\
\hline 11 & $\uparrow 2.972987$ & ADCY8 & adenylate cyclase 8 (brain) [Source:HGNC Symbol;Acc:239] [ENSCAFT00000001672] \\
\hline 12 & $\uparrow 2.596691$ & MARCO & $\begin{array}{l}\text { macrophage receptor with collagenous structure [Source:HGNC Symbol;Acc:6895] } \\
\text { [ENSCAFT00000007902] }\end{array}$ \\
\hline 13 & $\uparrow 2.486832$ & EMR3 & $\begin{array}{l}\text { Canis lupus familiaris egf-like module containing, mucin-like, hormone receptor-like } \\
3 \text { (EMR3), mRNA [NM_001038666] }\end{array}$ \\
\hline 14 & $\uparrow 2.31884$ & IL6 & Canis lupus familiaris interleukin 6 (interferon, beta 2) (IL6), mRNA [NM_001003301] \\
\hline 15 & $\uparrow 2.2737932$ & SRGN & $\begin{array}{l}\text { PREDICTED: Canis familiaris similar to Secretory granule proteoglycan core protein } \\
\text { precursor (Platelet proteoglycan core protein) (P.PG) (Hematopoetic } \\
\text { proteoglycan core protein) (Serglycin) (LOC609421), mRNA [XM_846674] }\end{array}$ \\
\hline 16 & $\uparrow 2.1735125$ & ELSPBP1 & Epididymal sperm-binding protein 1 ;ELSPBP1;ortholog \\
\hline 17 & $\uparrow 2.1602907$ & LEF1 & $\begin{array}{l}\text { PREDICTED: Canis familiaris similar to lymphoid enhancer binding factor-1, transcript } \\
\text { variant } 7 \text { (LOC478507), mRNA [XM_858241] }\end{array}$ \\
\hline 18 & $\uparrow 2.1465235$ & GAD1 & $\begin{array}{l}\text { Canis lupus familiaris glutamate decarboxylase } 1 \text { (brain, } 67 \mathrm{kDa} \text { ) (GAD1), mRNA } \\
\text { [NM_001097543] }\end{array}$ \\
\hline 19 & $\uparrow 2.0999904$ & CTRB1 & $\begin{array}{l}\text { PREDICTED: Canis familiaris similar to chymotrypsinogen B1, transcript variant } \\
1 \text { (LOC479650), mRNA [XM_536782] }\end{array}$ \\
\hline 20 & $\uparrow 2.0861115$ & IL15 & Interleukin-15;IL15;ortholog \\
\hline 21 & $\uparrow 2.001695$ & DDIT3 & DNA-damage-inducible transcript 3 [Source:HGNC Symbol;Acc:2726] [ENSCAFT00000000367] \\
\hline 22 & $\uparrow 1.975823$ & PCSK2 & $\begin{array}{l}\text { proprotein convertase subtilisin/kexin type } 2 \text { [Source:HGNC Symbol;Acc:8744] } \\
\text { [ENSCAFT00000008876] }\end{array}$ \\
\hline 23 & $\uparrow 1.9757178$ & GPM6A & $\begin{array}{l}\text { PREDICTED: Canis familiaris similar to glycoprotein M6A isoform 1, transcript variant } \\
6 \text { (LOC475641) }\end{array}$ \\
\hline 24 & $\uparrow 1.9687057$ & HLA-DQB1 & $\begin{array}{l}\text { Canis lupus familiaris major histocompatibility complex, class II, DQ beta } 1 \\
\text { (HLA-DQB1), mRNA [NM_001014381] }\end{array}$ \\
\hline 25 & $\uparrow 1.9438797$ & SLC30A8 & $\begin{array}{l}\text { solute carrier family } 30 \text { (zinc transporter), member } 8 \text { [Source:HGNC Symbol;Acc:20303] } \\
\text { [ENSCAFT00000001287] }\end{array}$ \\
\hline 26 & $\uparrow 1.9432139$ & LYZL6 & Q6UW30_HUMAN (Q6UW30) TKAL754, partial (63 \%) [TC51642] \\
\hline 27 & $\uparrow 1.8990102$ & CDA & cytidine deaminase [Source:HGNC Symbol;Acc:1712] [ENSCAFT00000023893] \\
\hline 28 & $\uparrow 1.8836564$ & NELL1 & $\begin{array}{l}\text { PREDICTED: Canis familiaris similar to nel-like } 1 \text { precursor (LOC476888), } \\
\text { mRNA [XM_534090] }\end{array}$ \\
\hline 29 & $\uparrow 1.8206882$ & CELA1 & $\begin{array}{l}\text { Canis lupus familiaris chymotrypsin-like elastase family, member } 1 \text { (CELA1), } \\
\text { mRNA [NM_001003007] }\end{array}$ \\
\hline 30 & $\uparrow 1.8029478$ & CAMP & Canis lupus familiaris cathelicidin antimicrobial peptide (CAMP), mRNA [NM_001003359] \\
\hline 31 & $\uparrow 1.7610306$ & ERGIC2 & Endoplasmic reticulum-Golgi intermediate compartment protein 2 ;ERGIC2;ortholog \\
\hline 32 & $\uparrow 1.7566903$ & PRKCQ & protein kinase C, theta [Source:HGNC Symbol;Acc:9410] [ENSCAFT00000008336] \\
\hline
\end{tabular}


Table 2 (continued)

\begin{tabular}{|c|c|c|c|}
\hline & Fold Change & Gene symbol & Description \\
\hline 33 & $\uparrow 1.7566395$ & TFPI2 & tissue factor pathway inhibitor 2 [Source:HGNC Symbol;Acc:11761] [ENSCAFT00000023103] \\
\hline 34 & $\uparrow 1.7506666$ & LAMP3 & $\begin{array}{l}\text { lysosomal-associated membrane protein } 3 \text { [Source:HGNC Symbol;Acc:14582] } \\
\text { [ENSCAFT00000018703] }\end{array}$ \\
\hline 35 & $\uparrow 1.725342$ & S100P & S100 calcium binding protein P [Source:HGNC Symbol;Acc:10504] [ENSCAFT00000022770] \\
\hline 36 & $\uparrow 1.7065927$ & TREM1 & $\begin{array}{l}\text { triggering receptor expressed on myeloid cells } 1 \text { [Source:HGNC Symbol;Acc:17760] } \\
\text { [ENSCAFT00000002493] }\end{array}$ \\
\hline 37 & $\uparrow 1.6830823$ & BCL2A1 & BCL2-related protein A1 [Source:HGNC Symbol;Acc:991] [ENSCAFT00000022179] \\
\hline 38 & $\uparrow 1.6449332$ & IL33 & Canis lupus familiaris interleukin 33 (IL33), mRNA [NM_001003180] \\
\hline 39 & $\uparrow 1.597691$ & AREGB & amphiregulin B \\
\hline
\end{tabular}

protein expression was performed (data not shown). The tumour types of specimens were classified based on the World Health Organization (WHO) Histological Classification and Mammary Tumours of the Dog and Cat classification (Misdorp et al. 1999). Histological tumour grading was conducted on HE-stained sections using a Misdorp classification (2002). The mammary carcinoma grading was assessed in respect to tubule formation, degree of differentiation and mitotic index as. All the tumours examined were classified as the 1st grade of malignancy or the 3rd grade of malignancy (6 tumours in each group). Unfortunately survival data of these dogs is unavailable.

\section{Microarray analyses}

The total RNA from the samples was isolated using a Total RNA kit (A\&A Biotechnology, Poland) according to the manufacturer's protocol. Isolated RNA samples were dissolved in RNase-free water. The quantity of RNA was measured using NanoDrop (NanoDrop Technologies USA). The samples with adequate amounts of RNA were treated with DNaseI to eliminate a possibility of DNA contamination. The samples were subsequently purified using RNeasy MiniElute Cleanup Kit (Qiagen, Germany). Finally RNA samples were analyzed using BioAnalyzer (Agilent, USA) to measure the final RNA quality and integrity.

The Quick Amp Labeling Kit (Agilent, USA) was used to amplify and label target RNA to generate complementary RNA (cRNA) for oligo microarrays used in gene expression profiling and other downstream analyses. The gene expression of the poorly differentiated, most malignant tumours was compared against the gene expression of the well differentiated tumours (the 1st grade of malignancy). Samples were examined in four repetitions (two dye-swaps to eliminate the effect of label factor). Thus, each biological condition was labelled once by $\mathrm{Cy} 3$ and once by Cy5. Taking the average of all labelled arrays, the dye effect on any particular gene was cancelled. The hybridization was performed with canine-specific AMADID Release GE 4x44K microarrays (Agilent, USA) using Gene Expression Hybridization Kit (Agilent, USA) according to the manufacturer's protocol.

Signal detection, quantification and analysis

Acquisition and analysis of hybridization intensities were performed using DNA microarray scanner (Agilent, USA). Then, the results were extracted using Agilent's Feature Extraction Software with normalization and robust statistical analyses. Results were analyzed for statistical purposes using Future Extraction and Gene Spring software (Agilent, USA). The unpaired t-test with Benjamin-Hochberg FDR $<5 \%$ (false discovery rate) correction was applied (with $p$ value cut-off $<0.01$ ). For further analysis we chose only these genes with values within upper and lower cut-off (100.00 and 20.00, respectively) in each of the slide, whose expression changed at least 1.5fold in each of examined slide. The area of the analyses covered in this publication has been deposited in NCBI's Gene Expression Omnibus and is accessible via GEO Series accession number GSE 44033.

Gene function was identified using the PANTHER pathway analysis software (Mi et al. 2005) and Pathway Studio software (Agilent, USA). PANTHER online platform allowed for wide analysis of the Canis familiaris regulated genes and also for statistical analysis of number of regulated genes involved in specific pathways or biological functions compared to the normal healthy cell of this specie.

Real-time qPCR

The mRNA sequences of the key genes were obtained from NCBI database. Primers were designed using PRIMER3 software (free on-line access) and checked using Oligo 
Table 3 The list of down-regulated genes $(\downarrow)$ in canine mammary cancers of the 3rd grade of malignancy compared with the canine mammary cancers of the 1st grade of malignancy. Data was analyzed using Gene Spring software (Agilent, USA), $p<0.005$, Fold change $>1.5$

Fold Change Gene Symbol Description

$1 \downarrow 1.5897567 \quad$ SMOC1

$2 \downarrow 1.6253631 \quad$ SERPINE1

$3 \downarrow 1.6317778 \quad$ GDPD2

$4 \downarrow 1.6928551 \quad$ TTC17

$5 \downarrow 1.7700043 \quad$ PIP

$6 \downarrow 1.9344714 \quad$ PPP2R2B

$7 \downarrow 1.9801016 \quad$ ACAN

$8 \quad \downarrow 2.0213842 \quad$ BMP7

$9 \downarrow \downarrow 2.0953069 \quad$ PPP6R3

$10 \downarrow 2.2811608 \quad$ NOTUM

$11 \downarrow 2.3086379 \quad$ PRSS16

$12 \downarrow 2.3557005 \quad$ LRP2

$13 \downarrow 2.3743253 \quad$ FMOD

$14 \downarrow 2.3969395 \quad$ FABP3

$15 \downarrow 2.5347118 \quad$ LALBA

$16 \downarrow 2.630961 \quad$ MYOC

$17 \downarrow 2.7111955 \quad$ LOX

$18 \downarrow 2.7223504 \quad$ SLC22A10

$19 \downarrow 2.7353601 \quad$ COL2A1

$20 \downarrow 2.74712 \quad$ ACSM4

$21 \quad \downarrow 2.8774078 \quad$ PAQR8

$22 \downarrow 3.2135046 \quad$ MGAT4C

$23 \downarrow 3.331683 \quad$ EPYC

$24 \downarrow 3.341357 \quad$ SERPINA9

$25 \downarrow 3.625558 \quad$ FXYD2

$26 \downarrow 4.1011486 \quad$ SCG2

$27 \downarrow 4.2103615 \quad$ RIPPLY1

$28 \downarrow 4.6913886 \quad$ TAF7L

$29 \downarrow 5.1920776 \quad$ MYH2

$30 \downarrow 5.9604554 \quad$ MYH1

$31 \quad \downarrow 7.348387 \quad$ POU1F1
SPARC related modular calcium binding 1 [Source:HGNC Symbol;Acc:20318] [ENSCAFT00000026288]

Canis lupus familiaris serpin peptidase inhibitor, clade E (nexin, plasminogen activator inhibitor type 1), member 1 (SERPINE1), mRNA [NM_001197095]

glycerophosphodiester phosphodiesterase domain containing 2 [Source:HGNC Symbol;Acc:25974] [ENSCAFT00000026677]

tetratricopeptide repeat domain 17 [Source:HGNC Symbol;Acc:25596] [ENSCAFT00000010834]

prolactin-induced protein [Source:HGNC Symbol;Acc:8993] [ENSCAFT00000005869]

PREDICTED: Canis familiaris similar to protein phosphatase 2 (formerly 2A), regulatory subunit B (PR 52), beta isoform isoform 1, transcript variant 1 (LOC478053), mRNA [XM_535231]

Canis lupus familiaris aggrecan (ACAN), mRNA [NM_001113455]

Bone morphogenetic protein 7 Fragment (BMP-7)(Osteogenic protein 1)(OP-1) [Source:UniProtKB/Swiss-Prot;Acc:P34819] [ENSCAFT00000019076]

PREDICTED: Canis familiaris similar to sporulation-induced transcript 4-associated protein, transcript variant 7 (LOC483688), mRNA [XM_858601]

notum pectinacetylesterase homolog (Drosophila) [Source:HGNC Symbol;Acc:27106] [ENSCAFT00000009543]

protease, serine, 16 (thymus) [Source:HGNC Symbol;Acc:9480] [ENSCAFT00000017667]

low density lipoprotein receptor-related protein 2 [Source:HGNC Symbol;Acc:6694] [ENSCAFT00000019396]

fibromodulin [Source:HGNC Symbol;Acc:3774] [ENSCAFT00000015038]

fatty acid binding protein 3, muscle and heart (mammary-derived growth inhibitor) [Source:HGNC Symbol; Acc:3557] [ENSCAFT00000017685]

Canis lupus familiaris lactalbumin, alpha- (LALBA), mRNA [NM_001003129]

Canis lupus familiaris myocilin, trabecular meshwork inducible glucocorticoid response (MYOC), mRNA [NM_001048030]

lysyl oxidase [Source:HGNC Symbol;Acc:6664] [ENSCAFT00000000805]

solute carrier family 22, member 10 [Source:HGNC Symbol;Acc:18057] [ENSCAFT00000024230]

Canis lupus familiaris collagen, type II, alpha 1 (COL2A1), mRNA [NM_001006951]

acyl-CoA synthetase medium-chain family member 4 [Source:HGNC Symbol;Acc:32016] [ENSCAFT00000028528]

progestin and adipoQ receptor family member VIII [Source:HGNC Symbol;Acc:15708] [ENSCAFT00000003464]

mannosyl (alpha-1,3-)-glycoprotein beta-1,4-N-acetylglucosaminyltransferase, isozyme C (putative) [Source:HGNC Symbol;Acc:30871] [ENSCAFT00000009653]

epiphycan [Source:HGNC Symbol;Acc:3053] [ENSCAFT00000009916]

serpin peptidase inhibitor, clade A (alpha-1 antiproteinase, antitrypsin), member 9

[Source:HGNC Symbol;Acc:15995] [ENSCAFT00000028000]

FXYD domain containing ion transport regulator 2 [Source:HGNC Symbol;Acc:4026] [ENSCAFT00000020395]

PREDICTED: Canis familiaris similar to Secretogranin-2 precursor (Secretogranin II) (SgII) (Chromogranin C), transcript variant 1 (LOC488550), mRNA [XM_545669]

PREDICTED: Canis familiaris similar to Down syndrome critical region homolog 6 (LOC610288), mRNA [XM_847751]

TAF7-like RNA polymerase II, TATA box binding protein (TBP)-associated factor, 50 kDa [Source:HGNC Symbol;Acc:11548] [ENSCAFT00000027954]

Canis lupus familiaris myosin, heavy chain 2, skeletal muscle, adult (MYH2), mRNA [NM_001076795]

Canis lupus familiaris myosin, heavy chain 1, skeletal muscle, adult (MYH1), mRNA [NM_001113717]

Canis lupus familiaris POU class 1 homeobox 1 (POU1F1), mRNA [NM_001006949] 
Fig. 2 Classification of up-regulated genes in canine mammary cancers of the $3 \mathrm{rd}$ grade of malignancy (a.) and in canine mammary cancers of the 1st grade of malignancy (b.) according to their involvement in biological processes (based on the PANTHER Database, www.pantherdb.org) a Go Biological Process

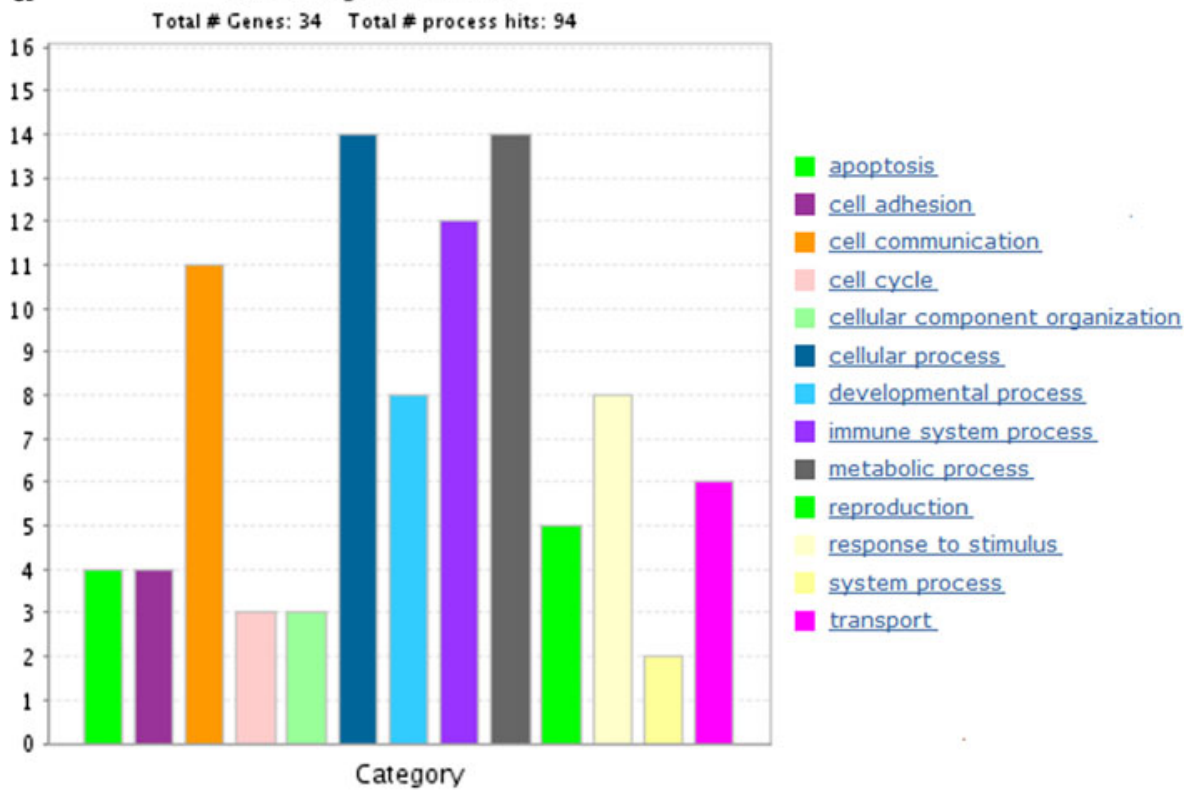

b Go Biological Process

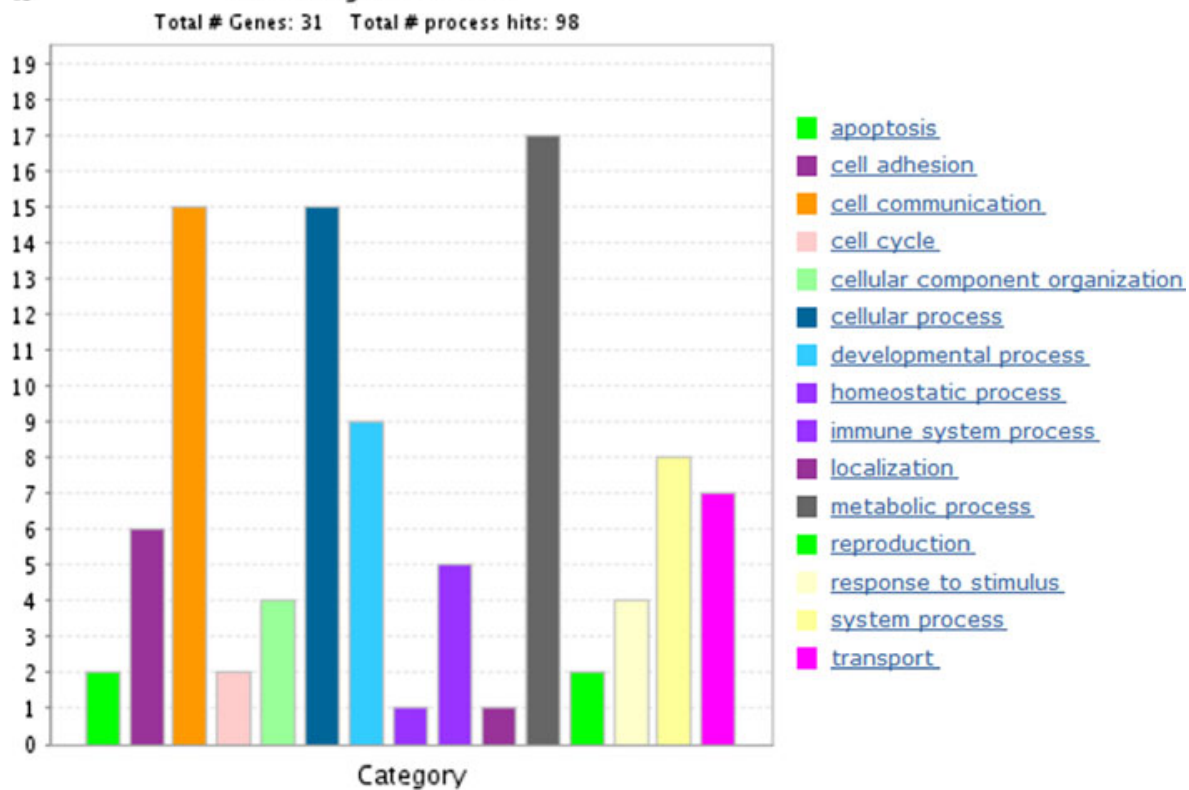

Calculator (free on-line access) and Primer-Blast (NCBI database). Primers' sequences are listed in Table 1. Rps19 gene was used as a non-regulated, reference gene for normalization of target gene expression (Brinkhof et al. 2006; Etschmann et al. 2006). Quantitative RT-PCR was performed using fluorogenic Lightcycler Fast Strand DNA Sybr Green (Roche) and the Light Cycler (Roche). The results were analyzed using comparative $\mathrm{Ct}$ method (Schmittgen and Livak 2008). Relative transcript abundance of the gene equals $\Delta \mathrm{Ct}$ values $\left(\Delta \mathrm{Ct}=\mathrm{Ct}^{\text {reference }}\right.$ $\left.\mathrm{Ct}^{\text {target }}\right)$. Relative gene expression is expressed as $\Delta \Delta \mathrm{Ct}$ value $\left(\Delta \Delta \mathrm{Ct}=2^{-\Delta \mathrm{Ct}}\right)$. The experiment was conducted in triplicates.
Then, to visualize the PCR product it was dedicated for electrophoresis in $2 \%$ agarose gel (Sigma Aldrich), stained with ethidium bromide (Sigma Aldrich) and run for $60 \mathrm{~min}$ at $90 \mathrm{mV}$ in $1 \times$ tris-borate-EDTA buffer. Then, the gel was visualized under UV light.

\section{Results}

Gene expression in canine mammary malignancy

The microarray-based transcriptional profile of the canine mammary cancers of the 3rd grade of malignancy was 


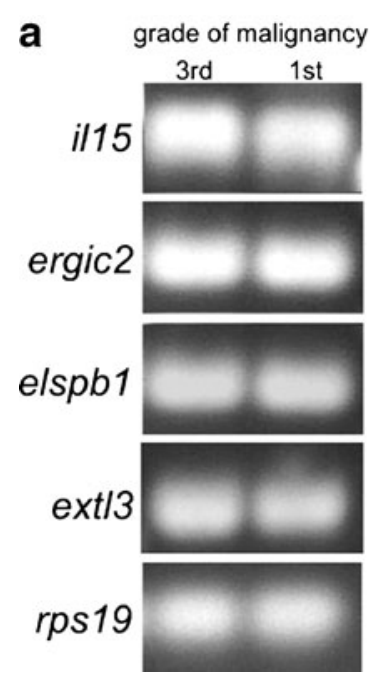

Fig. 3 Results for agarose gel electrophoresis of examined gene's PCR products following real time Sybr green amplification (a.). The RTqPCR expression of examined genes $(n=3)(\mathbf{b}$.). Estimated relative gene expression for each gene was compared between canine

compared to the canine mammary cancers of the 1st grade of malignancy used as a reference. For each comparison 2 separate dye-swap experiments were performed. This study showed 70 statistically significant $(p<0.005$; Fold change $=$ 1.5) regulated genes (Fig. 1). Further analysis showed 39 up-regulated genes (Table 2) and 31 down-regulated genes (Table 3) in canine mammary cancer of the 3 rd grade of malignancy.

\section{Function of identified genes}

PANTHER analysis of identified up-regulated genes showed that they were mainly involved in biological processes such as: cellular process (NELL2, NELL1, CNGA1, PRKCQ, S100P, EMR3, PCSK2, IL15, IL8, MARCO, IL6, CAMP, GPM6A, BCL2A1), metabolic process (MMP3, LEF1, ADCY8, CELA1, PRKCQ, LYZL6, TFPI2, S100P, MMP1, PCSK2, MTMR10, CAMP, AMP3, EXTL3) and developmental process (NELL2, NELL1, PRKCQ, EMR3, PCSK2, IL8, GPM6A, BCL2A1) (Fig. 2a). The most significant pathway in which up-regulated genes $(n=12)$ were involved was the inflammation mediated by chemokine and cytokine signaling pathway (HLA-DQB1, NELL1, LYZL6, S100P, TFPI2, TREM1, EMR3, IL6, IL8, IL15, MARCO, CAMP). Analysis of the down-regulated genes showed that they were involved mainly in metabolic process, cellular process, cell communication and developmental process (Fig. 2b). Pathway analysis showed that these genes were mainly involved in cytoskeletal regulation by Rho GTPase, GnRH receptor pathway, inflammation mediated by chemokine and cytokine, nicotinic acetylcholine receptor signaling pathway and Wnt signaling pathway. mammary carcinomas of the 3rd grade of malignancy and of the 1st grade of malignancy (ANOVA and Tukey test; Graph Pad Prism 3.0, USA). The $p$ value $<0.05$ was regarded as significant and marked as *, $p<0.001$ was regarded as highly significant and marked as **

\section{Real-time qPCR gene expression}

For the purpose of microarray data validation, we have randomly selected 4 genes: il15, ergic2, elspb1 and extl3. Realtime qPCR results showed similar trends in gene expression changes as were observed in microarray studies (Fig. 3). The expression of examined genes was higher in the most malignant canine mammary cancers than in the tumours of the $1 \mathrm{st}$ grade of malignancy.

\section{Discussion}

Canine mammary cancer constitutes a serious clinical problem. That is a reason why its molecular biology has been systematically examined during the last few years (Rao et al. 2009; Pawłowski et al. 2011, Klopfleish et al. 2010; Pawłowski et al. 2013).

The very interesting study was conducted by Klopfleisch et al. (2010) who identified a gene expression profile in canine mammary tumours that was associated with early metastatic spread to the lymph nodes. Based on the gene expression pattern of these tumours the authors were able to discriminate carcinomas with divergent metastatic potential despite similar histological features. Moreover, a partial overlap was found between the canine mammary "metastatic" gene expression profile and similar metastasis-associated gene expression "signature" of breast cancer (Veer et al. 2002).

Our previous study of gene expression in canine mammary tumours of various grade of malignancy showed that histological diagnosis was distinct from molecular diagnosis (Pawłowski et al. 2013). We have also identified cellular pathways and biological processes in which the most 
significant up-regulated genes were involved. In the tumours of the 3rd grade of malignancy we identified interesting upregulated cluster of genes related to immunological system. Their higher expression found in the most malignant cancers might be related with increased recruitment of hematopoietic cells into the tumour mass. Although the tumour is composed of various cells depending on the tumour type, myeloid cells seem to form a major component (Bingle et al. 2002). Clinical studies have shown a correlation between the number of myeloid cells (mainly macrophages) and a poor prognosis in many human cancers (e.g. breast, prostate, ovarian, etc.) (Jadus et al. 1996). Our own studies conducted on canine mammary cancers have not shown any correlation between number of macrophages in tumour mass and a grade of tumour malignancy (Król et al. 2011). However, interestingly we observed expression of myeloid cell antigens in cancer cell lines and tissues (Król et al. 2011,2012) which increased upon the co-culture of these both types of cells (Król et al. 2012). We have shown that expression of typical macrophage antigens (CD14, CSF-1R) in canine mammary cancer tissues correlated with the tumour grade of malignancy (Król et al. 2011). Similarly, Dr. Pollard (2008) described that a gene expression signature characteristic for macrophages was an independent predictor of poor outcome in follicular lymphoma. Thus, these genes were typed as new malignancy markers.

Based on these results, the aim of the presented study was two-fold: 1) to compare gene expression in canine mammary tumours of the 1 st and the 3rd grade malignancy in order to find new possible prognostic markers and 2) to validate whether genes characteristic for immunological system can constitute new markers of malignancy.

Similarly to our previous study (Pawłowski et al. 2013) we showed significant over-manifestation of genes related with chemokine and cytokine mediated signalling pathway (HLADQB1, NELL1, LYZL6, S100P, TFPI2, TREM1, EMR3, IL6, IL8, IL15, MARCO, CAMP) (Fig. 2, Tables 2 and 3). A few of these genes seemed to be particularly interesting. For example, $\mathrm{S} 100 \mathrm{P}$ calcium binding protein (which expression is regulated by androgens and IL6 - another up-regulated gene in the most malignant canine mammary tumours) is though as a new prognostic factor (Parkkila et al. 2008). A correlation was found between its increased expression and poor survival, cancer proliferation and increased resistance to chemotherapy (Maciejczyk et al. 2013). Our results are in accordance with clinical data as the cancers of high grade of malignancy (which express higher levels of S100P) are associated with an increased risk of death within 2 years after mastectomy (Karayannopoulou et al. 2005).

In the most malignant canine mammary cancers an increased expression of two metalloproteinases (MMPs): 1 and 3 was observed (Table 2). MMPs comprise a structurally and functionally related family degrading extracellular matrix and basement membrane barriers. That is why they are thought to play a key role in angiogenesis, inflammatory processes, cancer development and metastasis, as well as in proliferation and apoptosis (Sauter et al. 2008). Because of their role in the degradation of the extracellular matrix leading to tumor invasion and metastasis, they may also serve as prognostic markers (Pardo and Selman 2005, Brickerhoff and Matrisian 2002). In this context, MMPs have been focused on as targets for therapeutic strategies.

The metalloproteinases are also linked to specific aspects of an inflammatory or immune response, such as the generation of chemokine gradients or immune cell influx (Hojilla et al. 2008). In addition to the metalloproteinase-mediated generation of inflammation triggers, metalloproteinases are, in turn, utilized by immune cells to further propagate the inflammatory reaction. In breast cancer samples, MMPs are found in neutrophils, macrophages, and $\mathrm{T}$ lymphocytes as well as in cancer cells (Benaud et al. 1998).

Cancer development is a complex process. In addition to the cancer cell intrinsic factors, the cancer microenvironment composed of various cells influences the behavior of cancer cells. The results of our study indicate that in dogs the number of tumour-infiltrating myeloid cells or expression of myeloid-specific antigens by cancer cells is related to the cancer progression and may constitute a new marker of malignancy, however further studies in this field are required.

Acknowledgments This work was supported by grant no N N308 574940 from the Ministry of Sciences and Higher Education. The authors would like to thank prof. Dr. hab. Elżbieta Malicka and Dr. Izabella Dolka from Warsaw University of Life Sciences for histopathological diagnosis of examined canine mammary tumours.

Open Access This article is distributed under the terms of the Creative Commons Attribution License which permits any use, distribution, and reproduction in any medium, provided the original author(s) and the source are credited.

\section{References}

Benaud C, Dickson RB, Thompson EW (1998) Roles of the matrix metalloproteinases in mammary gland development and cancer. Breast Cancer Res Treat 50:97-116

Bingle L, Brown NJ, Lewis CE (2002) The role of tumor-associated macrophages in tumor progression: implications for new anticancer therapies. J Pathol 196:254-265

Brickerhoff CE, Matrisian LM (2002) Matrix metalloproteinases: a tail of a frog that became a prince. Nat Rev Mol Cell Biol 3:207-214

Brinkhof B, Spee B, Rothuizen J, Penning LC (2006) Development and evaluation of canine reference genes for accurate quantification of gene expression. Anal Biochem 356:36-43

Etschmann B, Wilcken B, Stoevesand K, von der Schulenburg A, Sterner-Kock A (2006) Selection of reference genes for quantitative real-time PCR analysis in canine mammary tumors using the GeNorm algorithm. Vet Pathol 43:934-942 
Hojilla CV, Wood GA, Khokha R (2008) Inflammation and breast cancer. Metalloproteinases as common effectors of inflammation and extracellular matrix breakdown in breast cancer. Breast Cancer Res 10:205

Jadus MR, Irwin MC, Irwin MR, Horansky RD, Sekhon S, Pepper KA, Kohn DB, Wepsic HT (1996) Macrophages can recognize and kill tumor cells bearing the membrane isoform of macrophage colonystimulating factor. Blood 87:5232-5241.

Karayannopoulou M, Kaldrymidou E, Constantiinidis TC, Dessiris A (2005) Histological grading and prognosis in dogs with mammary carcinomas: application of a human grading method. J Comp Pathol 133:246-252

Klopfleisch R, Lenze D, Hummel M, Gruber AD (2010) Metastatic canine mammary carcinomas can be identified by a gene expression profile that partly overlaps with human breast cancer profiles. BMC Cancer 10:618

Król M, Pawłowski KM, Majchrzak K, Dolka I, Abramowicz A, Szyszko K, Motyl T (2011) Density of tumor-associated macrophages (TAMs) and expression of their growth factor receptor MCSF-R and CD14 in canine mammary adenocarcinomas of various grade of malignancy and metastasis. Pol J Vet Sci 14:3-10

Król M, Pawłowski KM, Majchrzak K, Gajewska M, Majewska A, Motyl T (2012) Global gene expression profiles of canine macrophages and canine mammary cancer cells grown as a co-culture in vitro. BMC Vet Res 8:16

MacEwen EG (1990) Spontaneous tumors in dogs and cats: models for the study of cancer biology and treatment. Cancer Metastasis Rev 9:125-136

Maciejczyk A, Lacko A, Ekiert M, Jagoda E, Wysocka T, Matkowski R, Hałoń A, Gyorffy B, Lage H, Surowiak P (2013) Elevated nuclear S100P expression is associated with poor survival in early breast cancer patients. Histol Histopathol, ahead of publication

Manuali E, de Giuseppe A, Feliziani F, Forti K, Casciari C, Marchesi MC, Pacifico E, Pawłowski KM, Majchrzak K, Król M (2012) CA 15-3 cell lines and tissue expression in canine mammary cancer and the correlation between serum levels and tumour histological grade. BMC Vet Res 8:86

Mi H, Lazareva-Ulitsky B, Loo R, Kejariwal A, Vandergriff J, Rabkin S, Guo N, Muruganujan A, Doremieux O, Campbell MJ, Kitano H, Thomas PD (2005) The PANTHER database of protein families, subfamilies, functions and pathways. Nucleic Acids Res 33: D284-D288

Midsorp W (2002) Tumors of the mammary gland. In: Meuten DJ (ed) Tumors in domestic animals. Iowa State Press, Ames, pp 575-606

Misdorp W (1991) Progestagens and mammary tumours in dogs and cats. Acta Endocrinol 125(suppl 1):27-31
Misdorp W, Else RW, Hellme'n E, Lipscomb TP (1999) Histological classification of mammary tumors of the dog and the cat. Armed Forces Institute of Pathology and the American Registry of Pathology and The World Health Organization Collaborating Center for Worldwide Reference on Comparative Oncology, Washington, D.C., USA 7:11-29

Pardo A, Selman M (2005) MMP-1: the elder of the family. Int J Biochem Cell Biol 37:283-288

Parkkila S, Pan P, Ward A, Gibadulinova A, Oveckova I, Pasterkova S, Pastorek J, Martinez AR, Helin HO, Isola J (2008) The calciumbinding protein $\mathrm{S} 100 \mathrm{P}$ in normal and malignant human tissues. BMC Clin Pathol 8:2

Pawłowski KM, Majewska A, Szyszko K, Dolka I, Motyl T, Król M (2011) Gene expression pattern in canine mam mary osteosarcoma. Pol J Vet Sci 14:11-20

Pawłowski KM, Popielarz D, Szyszko K, Gajewska M, Motyl T, Król M (2012) Growth Hormone Receptor (ghr) RNAi decreases prolieration and enhances apoptosis in CMT-U27 canine mammary carcinoma cell lines. Vet Comp Oncol 10:2-15

Pawłowski KM, Maciejewski H, Dolka I, Mol JA, Motyl T, Król M (2013) Gene expression profiles of canine mammary carcinoma of various grade of malignancy. BMC Vet Res, in review

Pollard JW (2008) Macrophages define the invasive microenvironment in breast cancer. J Leukoc Biol 84:623-630

Rao NS, van Wolferen ME, Gracanin A, Bhatti SF, Krol M, Holdtege FC, Mol JA (2009) Gene expression profiles ofprogestin-induced canine mammary hyperplasia and spontaneous mammary tumors. J Physiol Pharmacol Supp 1:73-84

Russo IH, Russo J (1998) Role of hormones in mammary cancer initiation and progression. J Mammary Gland Biol Neoplasia 3:49-61

Sauter W, Rosenberger A, Beckmann L, Kropp S, Mittelstrass K, Timofeeva M, Wolke G, Steinwachs A, Scheinter D, Meese E, Sybrecht G, Kronenberg F, Deinermann H, Chang-Claude J, Illig T, Wichmann HE, Bickeboller H, Risch A (2008) Matrix Metalloproteinase 1 (MMP1) isassociated with early onset lung cancer. Cancer Epidemiol Biomarkers Prev 17:1127

Schmittgen TD, Livak KJ (2008) Analyzing real-time PCR data by the comparative $\mathrm{Ct}$ method. Nature Prot 3:1101-1108

Veer van't LJ, Bernards R (2008) Enabling personalized medicine through analysis of gene-expression patterns. Nature 452:564 570

Veer van't LJ, Dai H, Vijver can de MJ, He YD, Hart AA, Mao M, Peterse HL, Koy van der K, Marton MJ, Witteveen AT (2002) Gene expression profiling predicts clinical outcome of breast cancer. Nature 415(6871):530-536 